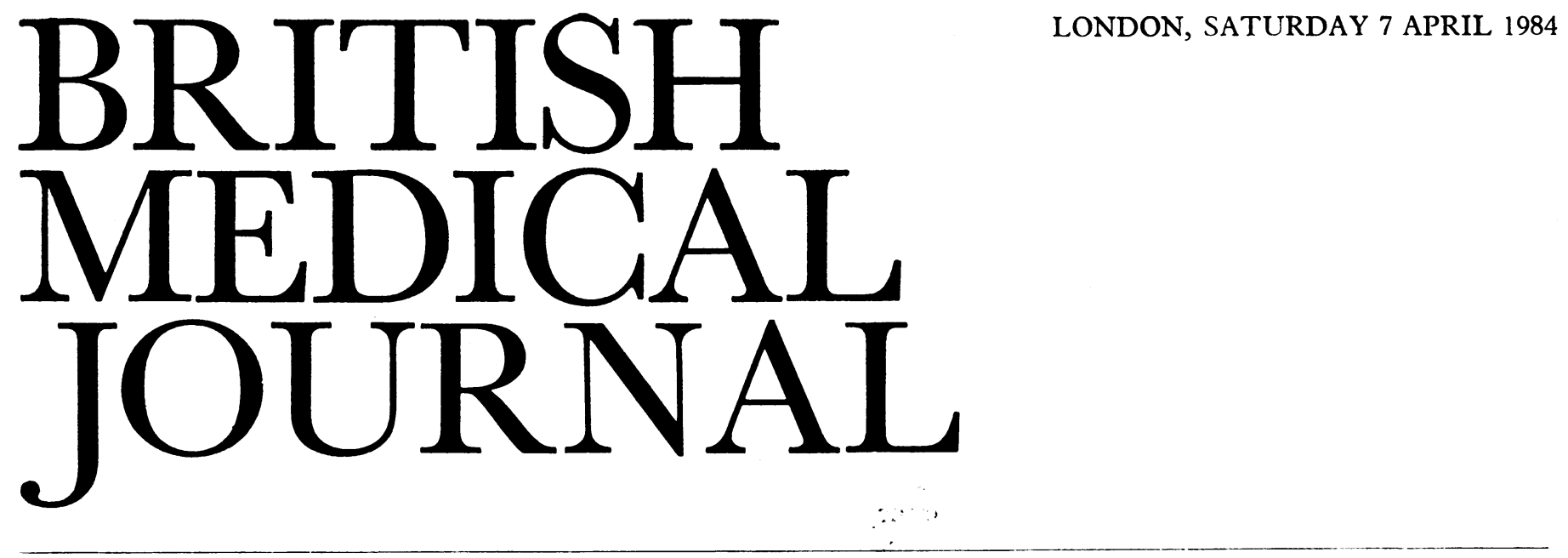

\title{
Auditing health care policies
}

Probably at no time in its 35 year history has the National Health Service aroused more interest, passion, and controversy than at present. Hardly a week goes by without a television programme about the "crisis of the NHS." Politically, it has become a central issue, with the Labour and the Alliance parties competing to denounce the government's record. Even the British Medical Association and the Confederation of Health Service Employees, among other trade unions representing NHS workers, appear to have found common ground in their anxieties about crumbling standards of health care in Britain today.

Yet the debate is more notable for the passion which the parties bring to it than for either the quality or quantity of the evidence that informs their case. It is an example of assertions in search of facts, of anecdotes, and of case histories substituting for any comprehensive analysis. All the more welcome, therefore, is the first attempt to provide a comprehensive survey of health care policies in Britain: the publication of Health Care UK 1984, described by the editors as "an economic, social and policy audit."1

The great advantage which Anthony Harrison and John Gretton bring to this venture is that of ignorance. Neither editor is a health care specialist. And unlike health care specialists, therefore, they were not put off from making the attempt by the knowledge of just how difficult a task they had set themselves. With the backing of the Chartered Institute of Public Finance and Accountancy, the Institute of Health Service Administrators, and the Nuffield Foundation, they plunged in where the experts feared to tread.

The outcome of the venture shows just how important it is to do simple things well: it may not be possible to climb Everest in a mackintosh and gym shoes but it is possible to get quite a long way in the foothills. If nothing else Health Care $U K 1984$ offers an invaluable compendium of basic facts and figures, ranging from trends in spending and staffing to consultation and strike rates. It brings together data otherwise scattered in a variety of government publications, House of Commons committee reports, and other sources to provide a comprehensive reference book.

But apart from its usefulness as a reference book, Health Care $U K 1984$ is also important as a corrective to the tunnel vision which so often characterises the debate. Its analysis does not deal exclusively with the NHS; instead it sets the expendi- ture and activities of the NHS into a wider context. Not only does it provide figures of spending on private health care-by now a familiar enough approach - but it also attempts to cost, albeit somewhat roughly, the cost of informal and self careput at $£ 450$ million a year each. It includes, furthermore, the cost of medical care provided by industry (an estimated $£ 100$ million a year), and covers such issues as occupational injuries. Above all, its analysis is informed by the realisation that the population's morbidity and mortality are affected by policies which are conventionally ignored in discussions of health care policy, notably the government's policies bearing on nutrition.

Clearly, there are dangers about adopting such a wide lens approach. Where do we stop? Taking a long view, it could be argued that the government's expenditure on social security benefits or housing may be more important for the state of the nation's health than spending on the NHS. In the immediate future, however, the NHS is left to cope with the ill health that may be generated by industry or by inadequate income maintenance policies. To try to be all embracing may be crucially important in theory but risks diverting attention from the practical, here and now problems of the NHS.

Paradoxically-though not surprisingly, given the conceptual and other difficulties-Health Care UK 1984 is weakest precisely when it attempts to "audit" the performance of the NHS. Once again, it usefully draws attention to some of the dimensions of performance which all too often are neglectednotably the way in which the NHS treats its own workers, consumers, and minority ethnic groups. But even here it encounters the problems which stem from the fact that we lack an adequate evaluative currency: that is, benchmark criteria derived from explicit policy aims. To show that many NHS workers are low paid tells us nothing, unless we assume that the service's objective ought to be to ensure adequate minimum incomes as distinct from paying the market rate. Nor is it as self evident as the editors appear to assume that the NHS ought to be responsive to consumer demands and complaints. One perverse effect of this might well be to weaken the attempts to divert resources to services for the most vulnerable groups like the elderly, the mentally ill, and handicapped-precisely those groups who can neither exit into the private sector nor exercise voice in the political market.

Equally troublesome are questions about whether the NHS is achieving its aims in terms of increasing equity in access to 
health care and of improving efficiency. Bravely and rightly the editors put these questions, even though their answers are less than wholly satisfactory. So far as equity is concerned the NHS does appear to be moving in the right direction. The geographical distribution of resources, prompted by the much criticised RAWP formula, is becoming more even, if very slowly. Indeed the performance of the NHS is rather better than the editors concede: they ignore the evidence that equity in terms of access to primary health care has been achieved even allowing for differences in need among social classes, though of course qualitative differences in the care received may still persist. ${ }^{2}$ But the evidence about efficiency, reviewed in Health Care UK 1984, is more ambiguous. If costs per case are declining, and if lengths of stay are falling, does this mean that standards of care are being reduced or that efficiency is increasing ? Like the government's own massive tome on performance indicators ${ }^{3}$ this compendium is better at prompting speculation than in providing an answer on issues such as these, even though it invokes the help of a variety of specialist contributors who provide background papers on some of the topics covered.

Presumably Health Care UK 1984 is designed to become an annual event, and indeed much of its usefulness would be lost if the information were not to be brought up to date regularly. Its value lies not only in making a vast mass of data readily accessible but also in providing a moving picture of trends and developments. The main advantage, however, that the editors have brought to the production of their first issue-the fact that, free from all institutional entanglements in the NHS, they have been able to take risks in interpreting the data-may turn out to be a perishable commodity. There will always be a place for a compendium of existing data which brings official statistics and academic research to a wider audience. But in the long run it is the quality of analysis which matters. If the notion of evaluating the performance of the NHS-or of health care policies in the wider sense-remains elusive, it is largely because the conceptual groundwork has not been done ${ }^{4}-$ a weakness which undermines the government's own performance indicators exercise as much as it affects this attempt at audit.

The existence of this intellectual vacuum is a formidable indictment of the Department of Health and Social Security's research policies over the decades and of the Medical Research Council's health services research programme in recent years. In retrospect the government's failure to adopt the recommendation of the Royal Commission on the National Health Service for the creation of an Institute of Health Services Research seems even more puzzling now than it did at the time. ${ }^{5}$ Perhaps the DHSS's new Health Services Supervisory Board-established in the wake of the Griffiths report ${ }^{6}-$ will set up the kind of institution needed to develop both the conceptual framework and the tools required if health care policies are to be properly evaluated. Certainly it is difficult to see how the board can carry out its job effectively in the absence of such an analysis of performance: it would be a company board without a balance sheet. In the mean time, however, its members will have to make do with Health Care $U K 1984$ and, for the time being at least, they could do a great deal worse.

\section{RUDOLF KLEIN}

Professor of Social Policy,

University of Bath,

Bath BA2 7AY

${ }^{1}$ Harrison A, Gretton J, eds. Health care UK 1984: an economic, social and policy audit. London: Chartered Institute of Public Finance and Accountancy, 1984.
- Collins E, Klein RE. Equity and the NHS: self-reported morbidity, access, and primary care. Br Med $\mathcal{F}$ 1980;281:1111-5.

${ }^{3}$ Department of Health and Social Security. Performance indicators: national summary for 1981. London: DHSS, 1983.

4 Klein RE. Performance, evaluation and the NHS. Public Administration $1982 ; 60: 385-407$

"Royal Commission on the National Health Service. Report. London: HMSO, 1979. (Cmnd 7615.)

' NHS Management Inquiry. Report. London: DHSS, 1983. (Griffiths report.)

\section{Combinations of $\beta$ lactam antibiotics}

Combinations of antibiotics are often used in treating serious infections, particularly when the infecting organism is not known and when the range of possible pathogens is very wide. Two antibiotics may provide increased broad spectrum cover and may give a synergistic effect against the infecting organism. ${ }^{1}$ One such combination widely used is a $\beta$ lactam antibiotic plus an aminoglycoside, and synergy between these two classes of antibiotics may readily be shown in the laboratory. Almost certainly this in vitro effect is translated into clinical benefit for the patient. ${ }^{2}$

Nevertheless, aminoglycoside toxicity may be a serious problem with such treatment. These antibiotics are often given to seriously ill patients who may have poor renal function and to immunocompromised patients who may receive prolonged or repeated courses of treatment. In such circumstances an alternative line is to give two $\beta$ lactam antibiotics together-for example, an antipseudomonal penicillin plus a $\beta$-lactamase stable, broad spectrum cephalosporin. A theoretical result of such a combination is an interaction between $\beta$ lactams. Is this possibility likely to be of clinical importance?

Laboratory studies of the effects of combinations of $\beta$ lactams on large numbers of bacterial isolates have shown mostly indifference or merely an additive effect. Occasionally, however, synergy or antagonism has been seen. ${ }^{3-6}$ At least two mechanisms may explain synergy. Firstly, different compounds may act at different target sites-the penicillin binding proteins in the bacterial cell wall-and sequentially interfere with synthesis of the cell wall. For example, mecillinam is synergistic with a range of other $\beta$ lactams, including benzylpenicillin, ampicillin, carbenicillin, cephalothin, and cephazolin. ${ }^{7}$ Mecillinam acts mainly at penicillin binding protein two, while the other agents act mainly at one and three. Unfortunately, most $\beta$ lactams act at penicillin binding proteins one and three, ${ }^{9}$ so that this type of synergy is uncommon. Nevertheless, Grunberg et al showed that the interaction occurred in vivo in experimental infections in mice. ${ }^{8}$

A second and more common mechanism of synergy is due to the inhibition of bacterial $\beta$-lactamases by some $\beta$ lactam antibiotics. Three requirements have been defined for synergistic action between $\beta$ lactams against a given micro-organism ${ }^{3}$ : firstly, the organism should produce $\beta$-lactamase; secondly, the $\beta$-lactamase must be capable of hydrolysing one of the agents (that is, that the organism must be resistant to that agent by virtue of $\beta$-lactamase production); and, finally, the other agent must be stable to and inhibit the $\beta$-lactamase concerned. Certain types of $\beta$-lactamase may be inhibited by many $\beta$ lactams, including cloxacillin, nafcillin, carbenicillin, 